\title{
Análise empírica do padrão de especialização do comércio internacional do estado do Acre $(1999-2016)^{1}$
}

\author{
Laís Viera Trevisan ${ }^{2}$ \\ Alison Geovani Schwingel Franck ${ }^{3}$ \\ Giulia Xisto de Oliveira ${ }^{4}$ \\ Rodrigo Abbade da Silva ${ }^{5}$ \\ Daniel Arruda Coronel ${ }^{6}$
}

\begin{abstract}
Resumo: Este trabalho buscou analisar o padrão de especialização do comércio internacional do estado do Acre, identificando os setores produtivos mais dinâmicos no período entre 1999 e 2016. Para isso, foram calculados os indicadores de Vantagem Comparativa Revelada Simétrica (IVCRS), de Comércio Intraindústria (CII), de Concentração Setorial das Exportações (ICS) e Taxa de Cobertura das Importações (TC), com os dados obtidos da Secretaria de Comércio Exterior - SECEX. Os resultados indicaram que a madeira foi o único setor cujos resultados do IVCRS apresentaram competitividade, demonstrando que ainda não existe uma diversificação do setor produtivo e, assim, da pauta exportadora, que continua a ser predominantemente composta por setores que se baseiam em recursos naturais. Quanto aos resultados do Cll, observa-se que o estado do Acre ainda não teve significativo impacto na integração regional por meio do aproveitamento do comércio intraindustrial. Além destes indicadores, o ICS revela que a pauta exportadora do estado é concentrada, e, ainda, a TC aponta que os setores de madeira, calçados e couro e alimentos, fumo e bebidas foram os que tiveram suas importações cobertas pelas respectivas exportações.
\end{abstract}

Palavras-chave: Competitividade. Comércio Internacional. Vantagens Comparativas.

Abstract: This study aimed to analyze the specialization pattern of international trade in the state of Acre, identifying the most dynamic productive sectors in the period between 1999 and 2016. In this sense, the Revealed Symmetric Comparative Advantage indicator (RSCA) was calculated, as well as the Intra-Industry Trade index (IIT), the Industry Concentration of Exports (ICS) and the Import Coverage Ratio (ICR), using data obtained from the Foreign Trade Office (SECEX). The results of the RSCA indicator showed that the wood sector was the only one to present competitiveness, demonstrating that there is still no diversification of the export basket in the state, which continues to be predominantly composed of sectors that are based on natural resources. Regarding the results of the IIT, it was observed that the state of Acre has not yet had a significant

${ }^{1}$ Este trabalho teve o aporte financeiro do Conselho Nacional de Desenvolvimento Científico e Tecnológico (CNPq), sendo que o projeto visa identificar o padrão de especialização comercial dos 26 estados da federação e mais o Distrito Federal.

2 Mestranda do Programa de Pós-Graduação em Gestão de Organizações Públicas (PPGOP) da Universidade Federal de Santa Maria (UFSM). laisvtrevisan@gmail.com

${ }^{3}$ Mestrando do Programa de Pós-Graduação em Administração (PPGA) da Universidade Federal de Santa Maria (UFSM). alischfranck@hotmail.com

4 Acadêmica do Curso de Administração da Universidade Federal de Santa Maria (UFSM). giuliaxisto@gmail.com

${ }^{5}$ Doutorando do Programa de Pós-Graduação em Administração (PPGA) da Universidade Federal de Santa Catarina (UFSC). abbaders@gmail.com

6 Doutor em Economia Aplicada. Professor Adjunto do Departamento de Ciências Administrativas e dos Programas de Pós-Graduação em Administração e em Gestão de Organizações Públicas da Universidade Federal de Santa Maria (UFSM).daniel.coronel@uol.com.br 
impact on regional integration through intra-industry trade. In addition to these indicators, the ICS revealed that the state's export basket is concentrated, and the ICR pointed out that the sectors of wood, footwear and leather, food, tobacco and beverages had their imports covered by the respective exports.

Keywords: Competitiveness. International Trade. Comparative Advantages.

\section{Introdução}

Nas últimas décadas, ocorreram mudanças na estrutura das exportações brasileiras, principalmente devido às estratégias comerciais e à expansão do comércio mundial. A partir do final da década 1980, o país começou a implementar medidas de livre comércio para modernizar o processo e tornar-se mais competitivo. Do mesmo modo, a globalização e a criação de blocos econômicos foram intensificadas com a justificativa de eliminar possíveis barreiras de mobilidade de capital, serviços ou bens entre países e regiões (HIDALGO; FEISTEL, 2013).

Para Marconi e Rocha (2012), as exportações têm um papel importante no desenvolvimento econômico do país, pois compõem a demanda agregada e estimulam a produção de um ou mais setores que geram encadeamentos produtivos e externam a outros setores, pois necessitam de adaptação aos padrões internacionais. Além disso, o autor afirma que os países emergentes que apresentam maior crescimento no mercado internacional são os que conseguem aperfeiçoar seus produtos, reduzir os custos e agregar valor.

Nesse contexto, a pauta do comércio intraindustrial representa a estrutura produtiva dinamizada através da tecnologia e da ampliação de mercados, já o comércio interindustrial é aquele que tem setores produtivos organizados pela concorrência e uso da dotação fatorial. Essas trocas comerciais permitem ganhos na participação do comércio internacional, constituindo uma vantagem comparativa revelada que pode ser medida pela relação entre os diferentes setores da organização, pois esses setores tendem a exportar os bens que melhor saibam produzir e importar os outros (ILHA; DORNELLES; WEGNER, 2009).

No cenário da produtividade de regiões específicas, novos mercados são conquistados por meio do aumento da complexidade interna da economia e geração de economia de escalas com maior eficiência produtiva, reduzindo os custos médios e a acumulação de capital, aumentando, dessa forma, o nível de emprego. Por isso, todas as 
atividades exportadoras se desenvolvem com o apoio de serviços específicos e com uma boa infraestrutura (MUNDURUCA; SANTANA, 2012).

Com base nesses conceitos, destaca-se a importância de se estudar a pauta exportadora dos estados brasileiros. Neste artigo, especificamente, será abordado o padrão de exportações do Acre e os impactos da sua abertura comercial, entre os anos 1999 e 2016, tendo em vista que o estado possui importante participação na exportação de alimentos, fumo e bebidas. Segundo dados do Instituto Brasileiro de Geografia e Estatística (IBGE, 2017), o Acre faz parte da Região Norte do Brasil, contando com uma área de $164.123,737 \mathrm{~km}^{2}$ e uma população, em 2017 , de 829.619 pessoas.

Com o intuito de analisar o padrão de especialização das transações do Acre e identificar os produtos e setores produtivos mais dinâmicos do estado, além de compreender a composição da sua pauta exportadora, entre os anos 1999 a 2016, foram utilizados os alguns indicadores. Estes foram: Indicador de Vantagem Comparativa Revelada Simétrica (IVCRS), Comércio Intraindústria (CII), Concentração Setorial das Exportações (ICS) e Taxa de Cobertura das Importações (TC).

O presente trabalho se estrutura em cinco seções, sendo a primeira esta introdução; a segunda uma contextualização das exportações do estado do Acre; a terceira apresenta o método de pesquisa utilizado; na quarta, apresentam-se os resultados e discussões, e, por fim, na quinta seção, encontram-se as conclusões.

\section{A estrutura das exportações do Acre}

De acordo com o Ministério do Desenvolvimento, Indústria e Comércio Exterior MDIC (2017a), as exportações do Acre apresentaram uma queda, pois o valor total exportado pelo estado, em 2015, era de US\$15,98 milhões, passando para US\$12,63 milhões em 2016. Esse decrescimento pode ser explicado pela diminuição da exportação da castanha, que é um dos principais produtos da pauta exportadora do estado. Contudo, as exportações de madeira, outro setor importante da economia acreana, apresentou crescimento (333,9\% em 2016), amenizando um pouco os resultados da queda das exportações daquela commodity. 
A Figura 1 apresenta as exportações do Acre, segundo fator agregado, entre os anos 1999 e 2016.

Figura 1- Exportações (X) do Acre segundo fator agregado (em milhões US\$ FOB)

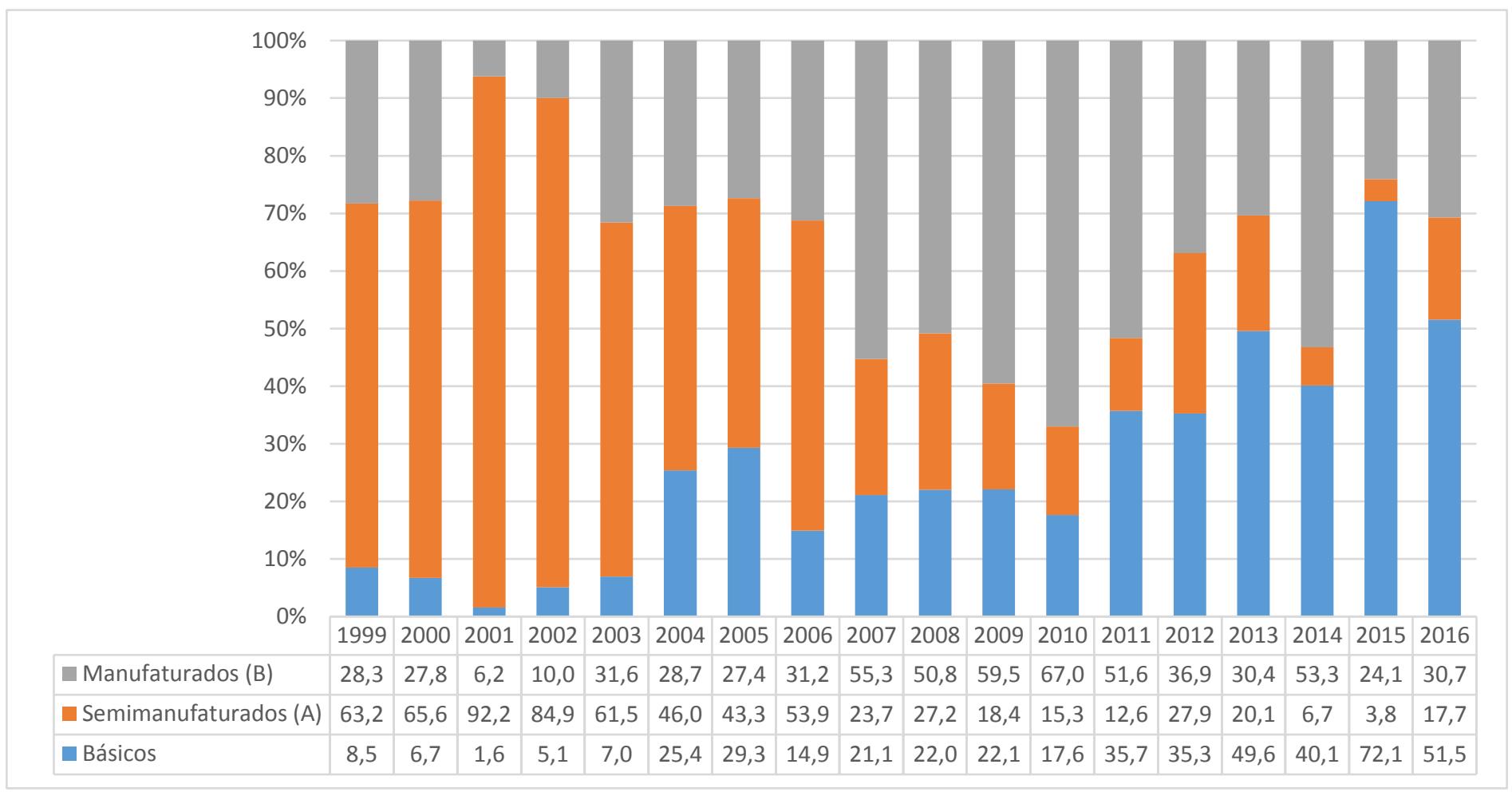

Fonte: Elaboração própria a partir dos dados MDIC/SECEX (2017b). 
Para Osorio (2016), o Acre e mais dezoito estados no Brasil têm uma Zona de Processamento de Exportação (ZPE), que são áreas de livre comércio exclusivas para industrialização das exportações. As ZPE não têm uma definição única, sendo vários os tipos de locais restritos onde se conferem incentivos governamentais contando com extraterritorialidades aduaneiras, separadas por barreiras físicas de seus países de origem. Seus principais objetivos são obter moeda estrangeira, criar empregos, atrair investimentos do exterior, desenvolver economicamente o país e diminuir as diferenças regionais existentes. O que leva os países e estados a adotarem as ZPE são objetivos competitivos perante o mercado internacional.

Atualmente, os produtos mais exportados pelo Acre são produtos básicos, com $51,5 \%$ de participação, seguidos dos produtos manufaturados $(30,7 \%)$, porém nem sempre essa foi a realidade. Observa-se que, entre os anos de 1999 a 2006, os produtos semimanufaturados eram os líderes das exportações; já de 2007 a 2012, os produtos manufaturados foram os mais exportados. Por fim, os básicos só começaram a liderar o ranking em 2013, mantendo o posto até 2016. A Figura 2 mostra as importações por fator agregado no Acre entre os anos 1999 e 2016. 
Figura 2- Importações (M) do Acre segundo fator agregado (em milhões US\$ FOB)

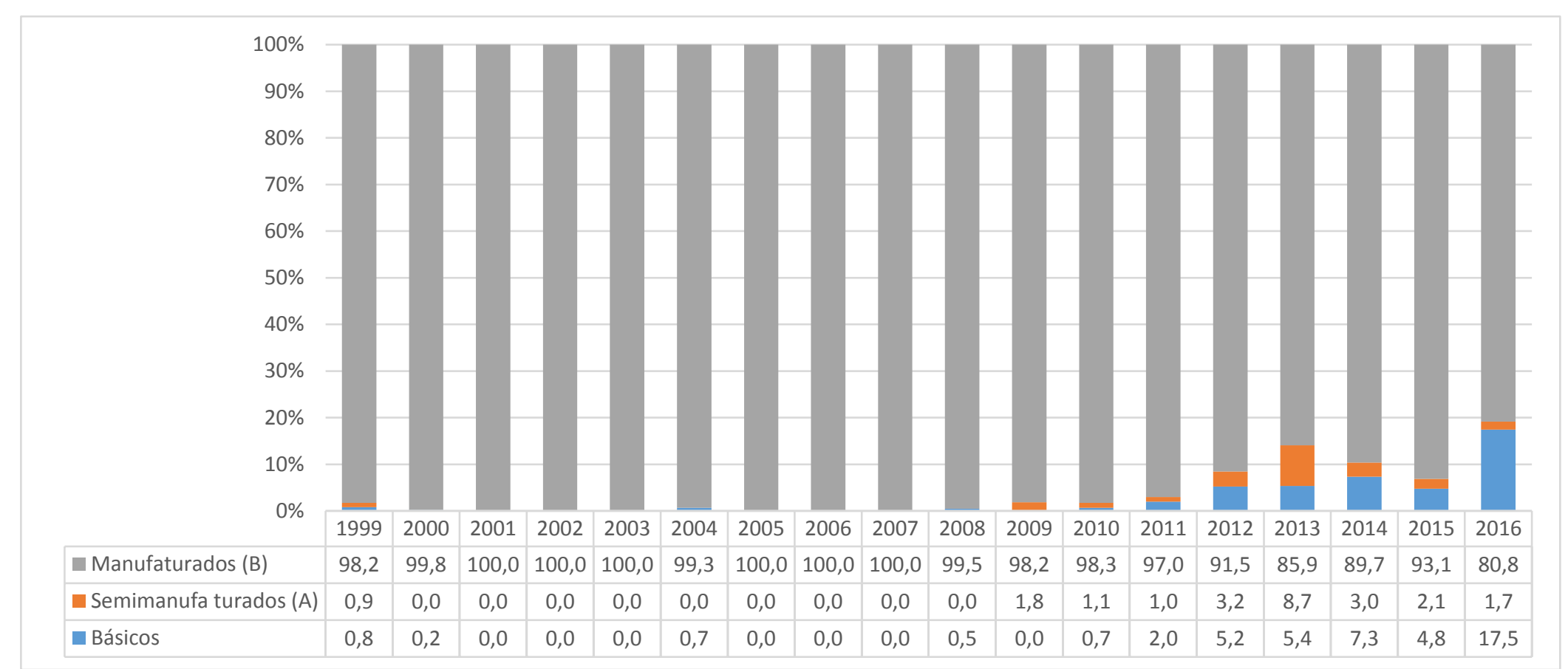

Fonte: Elaboração própria a partir dos dados MDIC/SECEX (2017b).

Conforme a Figura 2, as importações mantiveram um comportamento mais padronizado, se comparadas com as exportações, pois, em todos os anos analisados (1999 a 2016), os produtos manufaturados lideraram o ranking (80,5\% a 100\%). Em alguns anos, nota-se a presença de importações de produtos semimanufaturados ou básicos, mas não significativamente. Em 2013, os produtos semimanufaturados alcançaram o seu ápice, com 8,7\%, por conta do foco do estado em aumentar a produção de alimentos e bebidas (produtos básicos) para exportar. Esse fato acabou resultando num decréscimo em sua produção de madeira (produtos semimanufaturados), o que exigiu uma maior importação desta commodity. Já em 2016, observa-se um crescimento das importações de produtos básicos (17,5\%). 
Diante da relevância das exportações comerciais, analisaram-se os quatro principais destinos das exportações acreanas, entre 1999 e 2016, que, juntos, representaram 89,95\% e $69,51 \%$ do total exportado pelo estado, respectivamente. Em 1999, os Estados Unidos foram o destino de $34,51 \%$ das vendas do estado, seguido pela Argentina, Itália e Bolívia, conforme a Tabela 1.

Tabela1- Destino das exportações e sua participação no total exportado pelo Acre - 1999 e 2016

\begin{tabular}{cccccccc}
\hline Posição & $\begin{array}{c}\text { Países de } \\
\text { destino }\end{array}$ & $\begin{array}{c}\text { Exp. em 2016 } \\
\text { (milhões US\$ } \\
\text { FOB) }\end{array}$ & $\begin{array}{c}\text { Part. \% } \\
\text { em 2016 }\end{array}$ & Posição & Países de destino & $\begin{array}{c}\text { Exp. em 1999 } \\
\text { (milhões US\$ } \\
\text { FOB) }\end{array}$ & $\begin{array}{c}\text { Part. \% } \\
\text { em } \\
1999\end{array}$ \\
\hline $1^{\circ}$ & Bolívia & 4,05 & 32,09 & $1^{\circ}$ & Estados Unidos & 0,45 & 34,51 \\
$2^{\circ}$ & Peru & 3,46 & 27,37 & $2^{\circ}$ & Argentina & 0,33 & 25,62 \\
$3^{\circ}$ & Estados Unidos & 1,26 & 9,96 & $3^{\circ}$ & Itália & 0,23 & 17,95 \\
$13^{\circ}$ & Argentina & 0,09 & 0,71 & $4^{\circ}$ & Bolívia & 0,15 & 11,87 \\
$<30^{\circ *}$ & Itália & $<0,01$ & 0,09 & $<30^{\circ *}$ & Peru & $<0,01$ & 0,00 \\
& Demais Países & 3,77 & 29,87 & & Demais Países & 0,13 & 10,06 \\
& Total & 12,63 & 100,00 & & Total & 1,29 & 100,00 \\
\hline
\end{tabular}

Legenda: * número muito próximo de zero

Fonte: Elaboração própria a partir dos dados MDIC/SECEX (2017b).

De 1999 a 2016, ocorreram algumas mudanças nos destinos das exportações acreanas. Dos quatro principais destinos, em 1999, os Estados Unidos ocupavam o 10 lugar no ranking, passando para o 3 o lugar em 2016. A Argentina, que ocupava o 2 o lugar em 1999, passa a ser o 13 em 2016; a Itália, que era o 3 em 1999, passa a não estar mais entre os mais importantes; já a Bolívia, que ocupava o 4 o lugar em 1999, em 2016, ocupa agora o 10 , e, por fim, o Peru, que não estava entre os principais destinos em 1999, passa a ser o 20 país que mais importa do estado do Acre em 2016.

A Tabela 2 apresenta a estrutura das exportações do Acre segundo grupos de produtos/setores. Os quatro setores que apresentaram maior média de participação percentual nas exportações totais do Acre, em 1999, foram madeira (69,6\%), calçados/couro (18\%), alimentos/fumo/bebidas (8,6\%) e minerais não metais e metais preciosos (3,8\%). Já em 2016, foram alimentos/fumo/bebidas $(51,9 \%)$, madeira $(29,1 \%)$, metais comuns $(8,6 \%)$ e máquinas e equipamentos (3,9\%). 
As maiores taxas de crescimento das exportações foram nos setores de metais comuns (1088870900,0\%), máquinas e equipamentos (496549900,0\%), químicos (157625900,0\%) e material de transporte (96797900,0\%). Contudo, há dois setores com decrescimento de $100 \%$, como é o caso de ótica e instrumentos e calçados/couro.

Um dos setores mais dinâmicos das exportações do Acre é o da madeira, que, segundo Castro, Fernandes e Carvalho (2012), exerce um relevante papel na cadeia produtiva do setor florestal e também no suprimento de uma rede de varejistas da região, pois abastece o segmento de painéis de madeiras, sendo o setor moveleiro o que mais absorve essa produção. O autor ressalta ainda que a empresa Laminados Triunfo, especializada em madeira tropical certificada do Brasil, é responsável por $70 \%$ do PIB das exportações do Acre.

Silva (2015) também afirma que, ao longo do processo de desenvolvimento econômico do estado do Acre, um dos pilares da economia foi o extrativismo vegetal, tendo a borracha natural como líder impulsionadora da economia por mais de 70 anos. 0 cenário internacional influenciou o desenvolvimento da atividade de extração vegetal no estado. Além disso, após a Segunda Revolução Industrial e a Segunda Guerra Mundial, surgiram os ciclos da borracha, sendo o primeiro de 1879 a 1912, e o segundo, de 1942 a 1945 . O primeiro foi encerrado devido ao surgimento de seringais de cultivo na Malásia, e o segundo ciclo finalizou conjuntamente com a Segunda Guerra Mundial. Ao finalizarem esses ciclos, observou-se uma desestruturação da economia do látex no Acre, e até mesmo em toda Região Norte do Brasil, trazendo à economia acreana alguns problemas sociais, ambientais e econômicos, dada a estagnação do setor gumífero7.

Segundo dados do MDIC (2017), outros produtos relevantes para as exportações do Acre são castanha do Pará (castanha do Brasil), que representou 38\% das exportações do estado em 2016; madeiras perfilada, compensada e serrada (28,3\% em 2016); miudezas de animais, comestíveis (6,1\% em 2016), tripas e buchos de animais (3,7\% em 2016), e milho em grãos (2,1\% em 2016). Já em 2015, 70\% das exportações do estado foram de castanha do Brasil, e $11 \%$, de madeiras perfilada e compensada.

\footnotetext{
${ }^{7}$ Setor responsável pela borracha.
} 
Tabela 2 - Estrutura das exportações do Acre segundo grupos de produtos/setores em (\%)

Setores/períodos

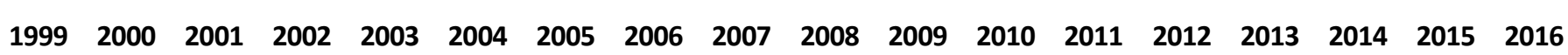

Taxa

de cresc.

1999 a 2016

\begin{tabular}{|c|c|c|c|c|c|c|c|c|c|c|c|c|c|c|c|c|c|c|c|}
\hline Alimentos/fumo/bebidas & 8,6 & 3,1 & 1,4 & 5,2 & 9,0 & 26,1 & 29,6 & 14,7 & 20,9 & 22,0 & 22,5 & 19,0 & 36,2 & 35,2 & 51,3 & 41,7 & 72,2 & 51,9 & 5836,4 \\
\hline Minerais & 0,0 & 3,6 & 0,0 & 0,0 & 0,0 & 3,2 & 2,0 & 0,5 & 0,1 & 0,0 & 0,2 & 0,1 & 0,2 & 0,1 & 0,0 & 0,5 & 0,3 & 0,2 & 22706900,0 \\
\hline Químicos & 0,0 & 0,0 & 0,1 & 0,0 & 0,2 & 1,0 & 1,1 & 0,9 & 1,3 & 0,2 & 1,9 & 0,7 & 0,6 & 1,2 & 2,0 & 4,7 & 1,5 & 1,2 & 157625900,0 \\
\hline Plástico/borracha & 0,0 & 1,8 & 0,9 & 2,3 & 0,6 & 2,5 & 2,1 & 1,9 & 2,5 & 0,2 & 2,9 & 1,6 & 0,6 & 2,2 & 0,7 & 1,9 & 0,4 & 3,2 & 97388,2 \\
\hline Calçados/couro & 18,0 & 21,9 & 76,5 & 3,1 & 14,4 & 0,0 & 15,8 & 22,8 & 0,2 & 0,0 & 0,0 & 2,3 & 0,0 & 0,0 & 0,0 & 2,1 & 0,1 & 0,0 & $-100,0$ \\
\hline Madeira & 69,6 & 62,3 & 18,9 & 86,9 & 72,5 & 60,2 & 44,4 & 48,4 & 70,2 & 76,6 & 61,9 & 71,9 & 61,2 & 56,9 & 32,6 & 33,4 & 14,8 & 29,1 & 308,3 \\
\hline Papel & 0,0 & 0,0 & 0,0 & 0,0 & 0,3 & 0,5 & 0,0 & 0,0 & 0,1 & 0,0 & 0,0 & 0,0 & 0,0 & 0,0 & 0,1 & 0,1 & 0,1 & 0,0 & 5919900,0 \\
\hline Têxtil & 0,0 & 0,1 & 0,0 & 0,0 & 0,1 & 0,1 & 0,1 & 0,0 & 0,0 & 0,0 & 0,1 & 0,0 & 0,0 & 0,1 & 0,5 & 0,0 & 0,0 & 0,0 & 310,8 \\
\hline Min. N.-met/met. Preciosos & 3,8 & 0,2 & 0,2 & 0,0 & 0,1 & 2,3 & 2,4 & 2,3 & 2,6 & 0,7 & 6,0 & 2,8 & 0,1 & 0,5 & 1,4 & 0,5 & 0,4 & 0,3 & $-13,4$ \\
\hline Metais comuns & 0,0 & 0,0 & 0,0 & 0,0 & 0,0 & 1,6 & 1,6 & 0,7 & 0,7 & 0,1 & 2,7 & 0,6 & 0,4 & 3,4 & 7,9 & 11,4 & 7,5 & 8,6 & 1088870900,0 \\
\hline Máquinas/equipamentos & 0,0 & 1,2 & 0,5 & 1,8 & 0,0 & 1,8 & 0,6 & 0,9 & 0,9 & 0,1 & 1,5 & 0,6 & 0,5 & 0,3 & 3,4 & 2,6 & 0,7 & 3,9 & 496549900,0 \\
\hline Material transporte & 0,0 & 0,0 & 0,0 & 0,0 & 0,0 & 0,3 & 0,0 & 0,3 & 0,3 & 0,0 & 0,0 & 0,0 & 0,0 & 0,1 & 0,0 & 0,7 & 1,9 & 0,8 & 96797900,0 \\
\hline Ótica/instrumentos & 0,0 & 0,0 & 0,0 & 0,0 & 0,0 & 0,0 & 0,0 & 6,5 & 0,0 & 0,0 & 0,0 & 0,0 & 0,0 & 0,0 & 0,0 & 0,0 & 0,0 & 0,0 & $-100,0$ \\
\hline Outros & 0,0 & 5,8 & 1,5 & 0,7 & 2,9 & 0,4 & 0,2 & 0,1 & 0,2 & 0,0 & 0,2 & 0,3 & 0,2 & 0,0 & 0,1 & 0,3 & 0,1 & 0,7 & 86273900,0 \\
\hline Total & 100,0 & 100,0 & 100,0 & 100,0 & 100,0 & 100,0 & 100,0 & 100,0 & 100,0 & 100,0 & 100,0 & 100,0 & 100,0 & 100,0 & 100,0 & 100,0 & 100,0 & 100,0 & 878,7 \\
\hline
\end{tabular}

Fonte: Elaboração própria a partir dos dados MDIC/SECEX (2017b). 


\section{Metodologia}

Na seção da metodologia, esboçam-se os quatro indicadores utilizados para o desenvolvimento deste estudo: Vantagem Comparativa Revelada Simétrica (IVCRS), de Comércio Intraindústria (CII), de Concentração Setorial das Exportações (ICS) e Taxa de Cobertura das Importações (TC), a partir de dados da Secretaria de Comércio Exterior - SECEX -, os quais objetivam demonstrar os setores do Acre com vantagens comparativas no comércio exterior, ou seja, os setores mais especializados no comércio internacional do estado do Acre.

\subsection{Indicadores de competitividade}

O primeiro indicador utilizado é o denominado Indicador de Vantagem Comparativa Revelada Simétrica (IVCRS), formalmente definido pela Expressão (1). O IVCRS revela a relação entre a participação de mercado do setor e a participação da região (estado) no total das exportações do país, fornecendo uma medida da estrutura relativa das exportações de uma região (estado). O IVCRS varia de forma linear entre -1 e 1 . 0 país que tiver resultado entre 0 e 1 terá vantagem comparativa no produto analisado. Se o IVCRS for igual a zero, terá competitividade média em relação aos demais exportadores, e, se variar entre -1 e 0, terá desvantagem comparativa (FRANCK et al., 2017).

Em que:

$$
\operatorname{IVCRS}_{i k}=\frac{\mathrm{x}_{i j} / \mathrm{x}_{i z}}{\mathrm{x}_{j} / \mathrm{x}_{z}}-1 / \frac{\mathrm{x}_{i j} / \mathrm{x}_{i z}}{\mathrm{x}_{j} / \mathrm{x}_{z}}+1
$$

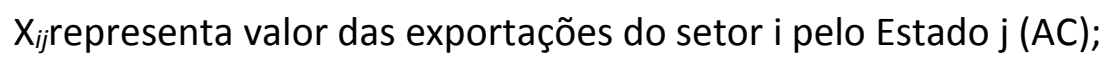

$\mathrm{X}_{i z}$ representa o valor das exportações do setor i da zona de referência z (Brasil);

Xjrepresenta valor total das exportações do estado j (AC); e,

$\mathrm{X}_{\mathrm{z}}$ representa valor total das exportações da zona de referência z (Brasil).

Quando uma região exporta um grande volume de um determinado produto em relação ao que é exportado desse mesmo produto pelo país, ela possui vantagem comparativa na produção desse bem. Além disso, em um ambiente cada vez mais globalizado e integrado, o fluxo comercial é caracterizado por um crescente comércio intraindústria (HIDALGO, 1998). A expansão do comércio nos processos de integração 
econômica, em geral, acontece por meio desse tipo de comércio. Assim, o conhecimento desse comércio é importante para uma economia na formulação de estratégias de inserção internacional (HIDALGO; DA MATA, 2004).

O segundo é o Índice de Comércio Intraindústria (CII), que visa caracterizar o comércio do estado do Acre. Este índice consiste na utilização da exportação e importação simultânea de produtos do mesmo setor. Com o avanço e difusão dos processos tecnológicos entre os países, mudam-se a configuração do comércio internacional e o peso das vantagens comparativas (abundância de recursos). Apresenta-se como destaque o crescimento do comércio interindustrial. Conforme Appleyard, Field Jr. e Cobb (2010), diferente do comércio interindustrial, o comércio intraindústria é explicado pelas economias de escala e pela diferenciação do produto.

O indicador setorial do comércio intraindustrial (CII) foi desenvolvido por Grubel e Lloyd (1975) e pode ser apresentado conforme a Equação 2:

$$
C I I=1-\frac{\sum_{i}\left|X_{i}-M_{i}\right|}{\sum_{i}\left(X_{i}+M_{i}\right)}
$$

Em que:

$\mathrm{X}_{\mathrm{i}}$ representa as exportações do produto $\mathrm{i}$;

Mirepresenta as importações do produto i.

Quando o indicador Cll aproximar-se de zero, pode-se concluir que há comércio interindustrial; neste caso, o comércio é explicado pelas vantagens comparativas, ou seja, observa-se a presença de comércio com países parceiros de produtos de diferentes setores do Acre. Esse evento pode ser observado quando da ocorrência de apenas importação, ou apenas exportação do setor i (ou produto i). Por outro lado, quando Cll for maior que $0,5(\mathrm{Cll}>0,5)$, o comércio é caracterizado como sendo intraindustrial.

Assim, o padrão de comércio intraindustrial reflete uma pauta exportadora que, por sua vez, sucede uma estrutura produtiva dinamizada em progresso tecnológico e em economias de escala (ampliação de mercados). Todavia, a configuração interindustrial reflete o ordenamento entre os setores produtivos, baseado no uso da dotação de fatores e sob concorrência perfeita. Esse arranjo explicativo das trocas comerciais pode indicar se determinado participante do comércio internacional alcançou ganhos de competitividade. 
Ressalta-se que, em meio à profusão de conceitos que foram dados a esse termo, entendese, neste artigo, diante dos alcances e das limitações dos índices utilizados, que alcançar competitividade internacional significa atingir os maiores níveis de vantagem comparativa revelada e o padrão de inserção intraindustrial (SILVA et al., 2017).

O terceiro indicador é o índice de Concentração Setorial das Exportações (ICS), também conhecido como coeficiente Gini-Hirchman, o qual quantifica a concentração das exportações de cada setor exportador i realizadas pelo estado j (Acre). O ICS é representado através da Equação 3:

$$
I C S_{i j}=\sqrt{\sum_{i}\left(\frac{X_{i j}}{X_{j}}\right)^{2}}
$$

Em que:

$X_{i j}$ representa as exportações do setor i pelo estado j (AC); e,

$\mathrm{X}_{\mathrm{j}}$ representa as exportações totais do estado $\mathrm{j}(\mathrm{AC})$.

O ICS varia entre 0 e 1, e, quanto mais próximo a 1 , mais concentradas serão as exportações em poucos setores, e, por outro lado, quanto mais próximo de 0 , mais diversificada será a composição da pauta de exportações (PAGANINI; FRAGA, 2014).

O quarto indicador é a Taxa de Cobertura das importações (TC), o qual indica quantas vezes o volume das exportações do setor i está cobrindo seu volume de importação. O índice é obtido através da seguinte Equação 4:

$$
T C_{i j}=\frac{X_{i j} / M_{i j}}{X_{i} / M_{i}}
$$

Em que:

Xij representa as exportações do setor i do Estado j (AC);

$M_{\mathrm{ij}}$ representa as importações do setor i do Estado j (AC);

$X_{i}$ representa as exportações do produto i; e,

$\mathrm{M}_{\mathrm{i}}$ representa as importações do produto i.

De acordo com Xavier e Silva (2007), o cálculo da taxa de cobertura se faz necessário para determinar os pontos fortes e fracos da economia em questão, e, quando a TCij é maior que a unidade, identifica-se uma vantagem comparativa em termos de cobertura das 
importações, ou seja, as exportações do setor i do Estado j teriam uma dimensão maior, quando comparadas às importações do mesmo setor.

Assim, por meio da comparação dos pontos fracos e dos pontos fortes entre diferentes setores, alterando-se um ponto fraco de um setor com um ponto forte de outro, é possível identificar os setores com melhores oportunidades de inserção comercial.

\subsection{Fonte de dados}

Para alcançar o objetivo de expor o padrão comercial da Acre, no período 1999 a 2016, e apresentar os setores com maior produtividade do estado, ou seja, aqueles que apresentam maior especialização e competitividade, foram utilizados indicadores baseados nos fluxos comerciais. O banco de dados para o cálculo destes indicadores encontra-se na Secretaria do Comércio Exterior (SECEX) do Ministério do Desenvolvimento, Indústria e Comércio do Brasil (MDIC, 2017b), acessível através do Sistema de Análise de Informações do Comércio Exterior - Aliceweb2 (ALICEWEB, 2017).

Os dados relativos às importações e às exportações desagregadas por setores seguem o padrão da literatura empírica da área, como apresentam Feistel (2008) e Maia (2005). Tais autores estabelecem capítulos divididos em setores produtivos, e, deste modo, cada capítulo corresponde a um agrupamento de produtos. Assim, obtêm-se os valores das importações e exportações, agregando-os ao padrão já utilizado por tais autores.

\section{Análise e discussão dos resultados}

\section{1 Índice de Vantagem Comparativa Revelada Simétrica - IVCRS}

A Tabela 3 demonstra a evolução do Índice de Vantagens Comparativas Reveladas Simétricas do Acre entre 1999 e 2016. Dos quatorze setores analisados, em apenas um o estado do Acre apresentou vantagens comparativas (IVCRS $>0$ ) em todos os anos da série histórica, e este setor foi o de madeira, o qual apresentou especialização permanente no que se refere à competitividade e à inserção acreana no mercado internacional. 
Tabela 3 - Índice de Vantagem Comparativa Revelada Simétrica para o Acre

\begin{tabular}{|c|c|c|c|c|c|c|c|c|c|c|c|c|c|c|c|c|c|c|}
\hline Grupos de Produtos/Ano & 1999 & 2000 & 2001 & 2002 & 2003 & 2004 & 2005 & 2006 & 2007 & 2008 & 2009 & 2010 & 2011 & 2012 & 2013 & 2014 & 2015 & 2016 \\
\hline Alimentos/fumo/bebidas & ,55 & 0,77 & $-0,91$ & $-0,69$ & $-0,53$ & $-0,05$ & 0,05 & & $-0,14$ & $-0,15$ & $-0,23$ & $-0,25$ & 0,07 & 0,02 & 0,18 & 0,06 & 0,30 & 0,16 \\
\hline Minerais & $-1,00$ & $-0,39$ & $-1,00$ & $-1,00$ & $-1,00$ & $-0,54$ & $-0,75$ & $-0,94$ & 090 & $-1,00$ & $-0,98$ & $-0,99$ & $-0,99$ & $-0,99$ & $-1,00$ & $-0,96$ & $-0,97$ & $-0,98$ \\
\hline Químicos & $-1,00$ & $-0,99$ & $-0,96$ & $-1,00$ & $-0,94$ & $-0,64$ & $-0,62$ & $-0,69$ & & $-0,92$ & $-0,49$ & $-0,77$ & $-0,79$ & & & & & $-0,60$ \\
\hline Plástico/borracha & $-0,98$ & $-0,28$ & $-0,49$ & $-0,08$ & $-0,69$ & $-0,06$ & $-0,16$ & $-0,24$ & & $-0,84$ & $-0,01$ & & & & & & & 0,07 \\
\hline Calçados/couro & 0,62 & 0,66 & 0,89 & $-0,17$ & 0,57 & $-0,97$ & 0,68 & 0,77 & & $-1,00$ & $-1,00$ & 0,13 & & & & 0,04 & & $-1,00$ \\
\hline Madeira & 0 & 0,92 & 0,76 & 0,93 & 0,92 & 0,90 & 0,89 & 0,91 & 0,94 & 0,96 & 0,96 & 0,97 & 0,98 & 0,97 & 0,95 & 0,94 & 0,85 & 0,91 \\
\hline Papel & $L, 00$ & $-1,00$ & $-1,00$ & & $-0,87$ & $-0,74$ & $-1,00$ & $-1,00$ & $-0,95$ & $-1,00$ & $-1,00$ & $-1,00$ & $-1,00$ & $-0,97$ & $-0,93$ & $-0,95$ & $-0,94$ & $-0,98$ \\
\hline Têxtil & $-1,00$ & $-0,95$ & $-1,00$ & $-1,00$ & $-0,95$ & $-0,91$ & $-0,94$ & $-0,96$ & $-0,96$ & $-0,99$ & $-0,89$ & $-0,95$ & $-0,97$ & $-0,84$ & $-0,35$ & $-0,95$ & $-1,00$ & $-1,00$ \\
\hline -met/met. Preciosos & 0,18 & $-0,87$ & $-0,86$ & $-0,96$ & $-0,91$ & 0,01 & 0,07 & 0,00 & 0,11 & $-0,45$ & 0,49 & 0,17 & $-0,90$ & $-0,60$ & $-0,22$ & $-0,65$ & $-0,75$ & $-0,79$ \\
\hline Metais comuns & $-1,00$ & $-1,00$ & $-1,00$ & $-1,00$ & $-1,00$ & $-0,75$ & $-0,75$ & $-0,88$ & $-0,88$ & $-0,98$ & $-0,50$ & $-0,85$ & $-0,90$ & $-0,37$ & 0,12 & 0,22 & $-0,04$ & 0,08 \\
\hline Máquinas/equipamentos & $-1,00$ & $-0,83$ & $-0,93$ & $-0,75$ & $-1,00$ & $-0,73$ & $-0,91$ & $-0,86$ & $-0,85$ & $-0,98$ & $-0,70$ & $-0,87$ & $-0,88$ & $-0,92$ & $-0,37$ & $-0,49$ & $-0,84$ & $-0,35$ \\
\hline Material transporte & $-1,00$ & $-1,00$ & $-1,00$ & $-1,00$ & $-1,00$ & $-0,95$ & $-1,00$ & $-0,95$ & $-0,96$ & $-1,00$ & $-0,99$ & $-1,00$ & $-1,00$ & $-0,99$ & $-1,00$ & $-0,82$ & $-0,64$ & $-0,87$ \\
\hline Ótica/instrumentos & $-1,00$ & $-1,00$ & $-1,00$ & $-1,00$ & $-1,00$ & $-0,86$ & $-0,98$ & 0,86 & $-1,00$ & $-1,00$ & $-0,98$ & $-1,00$ & $-1,00$ & $-1,00$ & $-1,00$ & $-1,00$ & $-1,00$ & $-1,00$ \\
\hline Outros & $-1,00$ & 0,63 & 0,10 & $-0,39$ & 0,39 & $-0,57$ & $-0,68$ & $-0,81$ & $-0,69$ & $-0,93$ & $-0,63$ & $-0,36$ & $-0,51$ & $-1,00$ & $-0,67$ & $-0,39$ & $-0,85$ & $-0,08$ \\
\hline
\end{tabular}

Fonte: Elaboração própria a partir dos dados MDIC/SECEX (2017b). 
Mesmo com o IVCRS positivo e próximo de 1 em quase todos os anos da pesquisa para o setor de madeira acreano, destaca-se que as exportações de madeira do estado ainda não atingiram todo o seu potencial. De acordo com Azevedo e Assreuy (2012), a história do Acre tem seus principais marcos relacionados à vida dos povos da floresta. A atualidade do estado é resultado da busca por sobrevivência na floresta e luta para sua preservação, com tentativas de garantir a subsistência dos povos de maneira sustentável. Assim, pode-se destacar que, no estado, busca-se um manejo sustentável comunitário da madeira. Ainda de acordo com os autores, foi finalizada, em 2012, a primeira Zona de Processamento de Exportação (ZPE) no Acre. Localizada próxima à capital Rio Branco, a ZPE do Acre foi pensada estrategicamente para exportar produtos pela rota do Pacífico, como a madeira e outros, em decorrência da proximidade. Essa ZPE tem capacidade para mais de trinta empresas e tem o objetivo de escoar a produção interna para os mercados externos.

Perante tal análise, sob a perspectiva das vantagens comparativas, compreende-se que o Acre possui poucos setores que apresentam vantagens comparativas, ou seja, possui uma pauta produtiva com pouca diversificação. Isso indica que o estado pode ser vulnerável às oscilações de variáveis externas (mudança de preços internacionais, crises, etc.) e internas (estiagens, etc.).

\section{2 Índice de Comércio Intraindústria - CII}

Na Tabela 4, apresentam-se os resultados do Cll, que representa o padrão comercial dentro de um mesmo setor, com os resultados para os quatorze setores analisados. Os resultados apontam que não há predominância do $\mathrm{Cll}$ em nenhum setor, o que indica que a relação do comércio interindústria ainda não é explorada de maneira plena pelo estado do Acre, o que pode ser considerado um dos pontos fracos da estrutura de comércio do mercado acreano. 
Tabela 4 - Índice de comércio intraindústria individual para o Acre

\begin{tabular}{|c|c|c|c|c|c|c|c|c|c|c|c|c|c|c|c|c|c|c|}
\hline Grupos de Produtos/Ano & 1999 & 2000 & 2001 & 2002 & 2003 & 2004 & 2005 & 2006 & 2007 & 2008 & 2009 & 2010 & 2011 & 2012 & 2013 & 2014 & 2015 & 2016 \\
\hline Alimentos/fumo/bebidas & 0,43 & 0,20 & 0,73 & 0,80 & 1,00 & 0,19 & 0,08 & 0,09 & 0,00 & 0,00 & 0,11 & 0,11 & 0,12 & 0,27 & 0,11 & 0,73 & 0,09 & 0,14 \\
\hline Minerais & 0,00 & 0,00 & 0,00 & 0,00 & 0,00 & 0,00 & 0,00 & 0,00 & 0,00 & 0,00 & 0,00 & 0,32 & 0,67 & 0,23 & 0,00 & 0,02 & 0,19 & 0,98 \\
\hline Químicos & 0,00 & 0,00 & 0,88 & 0,00 & 0,52 & 0,00 & 0,08 & 0,00 & 0,00 & 0,00 & 0,00 & 0,36 & 0,64 & 0,19 & 0,74 & 0,70 & 0,94 & 0,48 \\
\hline Plástico/borracha & 0,00 & 0,47 & 0,00 & 0,02 & 0,21 & 0,00 & 0,00 & 0,10 & 0,03 & 0,64 & 0,14 & 0,07 & 0,68 & 0,20 & 0,57 & 0,39 & 0,54 & 0,91 \\
\hline Calçados/couro & 0,00 & 0,00 & 0,00 & 0,00 & 0,00 & 0,00 & 0,00 & 0,00 & 0,00 & 0,00 & 0,00 & 0,00 & 0,47 & 0,00 & 0,00 & 0,00 & 0,00 & 0,00 \\
\hline Madeira & 0,01 & 0,00 & 0,00 & 0,00 & 0,00 & 0,00 & 0,00 & 0,00 & 0,00 & 0,00 & 0,01 & 0,00 & 0,01 & 0,05 & 0,09 & 0,21 & 0,11 & 0,02 \\
\hline Papel & 0,00 & 0,00 & 0,00 & 0,00 & 0,00 & 0,00 & 0,00 & 0,00 & 0,75 & 0,00 & 0,00 & 0,07 & 0,00 & 0,19 & 0,03 & 0,08 & 0,10 & 0,10 \\
\hline Têxtil & 0,00 & 0,00 & 0,00 & 0,00 & 0,00 & 0,00 & 0,00 & 0,00 & 0,00 & 0,00 & 0,87 & 0,00 & 0,76 & 0,77 & 0,04 & 0,21 & 0,03 & 0,00 \\
\hline Min. N.-met/met. Preciosos & 0,00 & 0,00 & 0,00 & 0,48 & 0,00 & 0,00 & 0,00 & 0,00 & 0,00 & 0,15 & 0,02 & 0,34 & 0,18 & 0,76 & 0,86 & 0,20 & 0,11 & 0,47 \\
\hline Metais comuns & 0,00 & 0,00 & 0,00 & 0,01 & 0,00 & 0,00 & 0,05 & 0,33 & 0,45 & 0,96 & 0,14 & 0,63 & 0,61 & 0,33 & 0,21 & 0,30 & 0,24 & 0,04 \\
\hline Máquinas/equipamentos & 0,00 & 0,01 & 0,01 & 0,04 & 0,00 & 0,71 & 0,39 & 0,34 & 0,24 & 0,07 & 0,50 & 0,14 & 0,05 & 0,05 & 0,64 & 0,13 & 0,05 & 0,69 \\
\hline Material transporte & 0,00 & 0,00 & 0,00 & 0,00 & 0,00 & 0,00 & 0,00 & 0,00 & 0,00 & 0,00 & 0,04 & 0,01 & 0,00 & 0,01 & 0,00 & 0,27 & 0,00 & 0,00 \\
\hline Ótica/instrumentos & 0,00 & 0,00 & 0,00 & 0,00 & 0,00 & 0,22 & 0,08 & 0,83 & 0,00 & 0,00 & 0,04 & 0,00 & 0,00 & 0,00 & 0,00 & 0,00 & 0,00 & 0,00 \\
\hline Outros & 0,00 & 0,00 & 0,00 & 0,00 & 0,00 & 0,00 & 0,00 & 0,00 & 0,00 & 0,00 & 0,00 & 0,00 & 0,62 & 0,00 & 0,80 & 0,49 & 0,19 & 0,38 \\
\hline
\end{tabular}

Fonte: Elaboração própria a partir dos dados MDIC/SECEX (2017b). 
Quanto à análise dos setores agregados no $\mathrm{CIl}$, os resultados também indicaram comércio interindústria para o Acre variando em torno de $10 \%$ entre 1999 e 2016 . Assim, em média, o Acre apresenta especialização no setor de madeira, o qual possui vantagens comparativas, conforme a Tabela 5.

Tabela 5 - Índice de comércio intraindústria - Cll agregado para o Acre

\begin{tabular}{cccc}
\hline Ano & CII & Ano & CII \\
\hline 1999 & 0,12 & 2008 & 0,01 \\
2000 & 0,02 & 2009 & 0,07 \\
2001 & 0,02 & 2010 & 0,06 \\
2002 & 0,07 & 2011 & 0,07 \\
2003 & 0,16 & 2012 & 0,12 \\
2004 & 0,09 & 2013 & 0,21 \\
2005 & 0,04 & 2014 & 0,34 \\
2006 & 0,12 & 2015 & 0,12 \\
2007 & 0,02 & 2016 & 0,19 \\
\hline
\end{tabular}

Fonte: Elaboração própria a partir dos dados MDIC/SECEX (2017b).

Em relação à ausência de comércio intraindutrial em todos os setores, apontada na análise desagregada, pode-se inferir que o estado do Acre ainda não obteve significativo impacto na integração regional por meio do aproveitamento do comércio intraindustrial.

4.3 Índice de Concentração Setorial das Exportações - ICS

O estado do Acre desempenhou um papel relevante na história da região amazônica durante a expansão da economia da borracha, no fim do século XIX, pelo potencial de riqueza natural dos rios acreanos e pela qualidade e produtividade dos seringais existentes. Nas últimas décadas do século $X X$, o Acre foi cenário do surgimento de organizações sociais e políticas inovadoras, baseadas na defesa do valor econômico dos recursos naturais. Assim, o estado acabou optando por um modelo de desenvolvimento que impacta a região até os dias de hoje, buscando conciliar o uso econômico das riquezas da floresta com a modernização de atividades que impactam o meio ambiente, reassumindo importância estratégica para o futuro da Amazônia (FARIAS, 2013). 
Diante desses aspectos da economia do estado, torna-se pertinente verificar se as suas exportações são concentradas. A Tabela 6 apresenta o grau de concentração das exportações - ICS do Acre.

Tabela 6 - Índice de concentração setorial das exportações para o Acre

\begin{tabular}{cccc}
\hline Ano & ICS & Ano & ICS \\
\hline 1999 & 0,73 & 2008 & 0,80 \\
2000 & 0,66 & 2009 & 0,66 \\
2001 & 0,79 & 2010 & 0,75 \\
2002 & 0,87 & 2011 & 0,71 \\
2003 & 0,75 & 2012 & 0,67 \\
2004 & 0,66 & 2013 & 0,61 \\
2005 & 0,56 & 2014 & 0,55 \\
2006 & 0,56 & 2015 & 0,74 \\
2007 & 0,73 & 2016 & 0,60 \\
\hline
\end{tabular}

Fonte: Elaboração própria a partir dos dados MDIC (2017b).

Como pode ser observado, é possível afirmar que o Acre apresenta uma pauta de exportações concentrada em poucos setores, visto que a média do indicador, no período analisado, foi de 0,69, oscilando entre 0,55 e 0,87. Esse resultado é reflexo das vantagens comparativas do estado, pois, de acordo com os resultados alcançados pelo IVCRS, apenas 7,14\% dos setores apresentaram vantagem comparativa. Já de acordo com o Cll, $100 \%$ dos setores apresentam comércio baseado em vantagens comparativas, ou seja, interindustrial.

De acordo com o MIDIC (2017a), ao longo do período, onze dos quatorze setores tiveram crescimento nas suas exportações. Ordenados, do setor com maior taxa de crescimento ao menor, segue-se a seguinte ordem: metais comuns; máquinas e equipamentos; químicos; material de transporte; outros; minerais; papel; plástico e borracha; alimentos, fumo e bebida; têxtil; e madeira. De acordo com a Tabela 3 (a qual engloba a análise horizontal), o setor de madeira (o único que apresentou IVCRS positivo) foi o que, mesmo tendo crescimento de exportações, apresentou o menor crescimento entre os onze setores. Entretanto, devido ao peso das exportações deste setor, corrobora-se a tendência de concentração das exportações do estado do Acre. 
4.4 Taxa de cobertura das importações - TC

Entre os setores com maiores taxas de cobertura (ou maior vantagem comparativa relativa às respectivas importações) ao longo da série, pode-se destacar o setor de madeira, cuja média de indicador foi de 6635150, apresentando a taxa de cobertura (TC>1) em todos os anos da pesquisa. Além do setor de madeira, merecem destaque os setores de calçados e couro (média de TC de 3635907) e o de alimentos, fumo e bebidas (média de TC de 191730), por terem TC acima de 1, na maioria dos anos da pesquisa, e manterem a TC (TC>1) predominantemente nos últimos anos da pesquisa, conforme a Tabela 7. Enquanto o setor de calçados e couro possui taxa de cobertura igual a 0 (TC=0), nos anos de 2008, 2009, 2013 e 2016, o setor de alimentos, fumo e bebidas indicou taxa de cobertura (TC>1) a partir de 2006. 
Tabela 7 - Taxa de cobertura do comércio do Acre- 1999 - 2016

\begin{tabular}{|c|c|c|c|c|c|c|c|c|c|c|c|c|c|c|c|c|c|c|}
\hline $\begin{array}{c}\text { Grupos de } \\
\text { Produtos/Ano }\end{array}$ & 1999 & 2000 & 2001 & 2002 & 2003 & 2004 & 2005 & 2006 & 2007 & 2008 & 2009 & 2010 & 2011 & 2012 & 2013 & 2014 & 2015 & 2016 \\
\hline $\begin{array}{l}\text { Alimentos/fumo } \\
\text { /bebidas }\end{array}$ & 0,16 & 0,42 & 0,52 & 0,63 & 0,15 & 0,60 & 0,95 & 2,28 & $\begin{array}{c}3451058 \\
89\end{array}$ & 46,71 & 1,50 & 2,45 & 6,05 & 3,12 & 3,15 & 2,28 & 8,39 & 1,75 \\
\hline Minerais & 0,57 & $\begin{array}{c}2085845 \\
72\end{array}$ & 0,00 & 0,00 & 0,00 & $\begin{array}{c}182079 \\
54 \\
59829,4\end{array}$ & $\begin{array}{c}98580,6 \\
0\end{array}$ & $\begin{array}{c}102690 \\
26 \\
180371\end{array}$ & $\begin{array}{c}9568,18 \\
219724,0\end{array}$ & $\begin{array}{l}3020,26 \\
22473,5\end{array}$ & $\begin{array}{l}32067 \\
20 \\
258250\end{array}$ & 0,03 & 0,20 & 0,06 & $\begin{array}{c}2576,9 \\
9\end{array}$ & 0,02 & 0,04 & 0,14 \\
\hline Quimicos & 0,57 & 14032,05 & 1,17 & 0,00 & 0,43 & 1 & 0,96 & 12 & 0 & 9 & ,92 & 0,65 & 0,84 & 4,53 & 0,10 & 0,71 & 0,45 & 0,04 \\
\hline Plástico/borracha & 2378,57 & 12,47 & 649,75 & 86,41 & 1,29 & $\begin{array}{c}140462 \\
34\end{array}$ & 18,09 & 2,07 & 5,14 & 0,11 & 1,22 & 3,82 & 0,78 & 4,40 & 0,45 & 5,51 & 0,15 & 0,16 \\
\hline Calçados/couro & $\begin{array}{c}1331777 \\
, 18\end{array}$ & $\begin{array}{c}1266741 \\
6,90\end{array}$ & $\begin{array}{c}4094045 \\
8,61\end{array}$ & $\begin{array}{l}1123519 \\
79\end{array}$ & $\begin{array}{c}1178030 \\
, 22\end{array}$ & 2592,59 & $\begin{array}{c}792343 \\
86\end{array}$ & $\begin{array}{c}4611197 \\
, 20\end{array}$ & 27251,46 & 0,00 & 0,00 & $\begin{array}{c}687434 \\
, 35\end{array}$ & 0,12 & $\begin{array}{c}14532 \\
87\end{array}$ & 0,00 & $\begin{array}{l}20232 \\
77,51\end{array}$ & $\begin{array}{c}46489,7 \\
6\end{array}$ & 0,00 \\
\hline Madeira & 77,66 & $\begin{array}{c}3597765 \\
2,99\end{array}$ & $\begin{array}{c}1014107 \\
2,02\end{array}$ & $\begin{array}{c}3159387 \\
2,30\end{array}$ & $\begin{array}{c}5930588 \\
, 66 \\
21813,8\end{array}$ & $\begin{array}{c}3450461 \\
, 36 \\
26558,2\end{array}$ & $\begin{array}{c}2226623 \\
, 40\end{array}$ & $\begin{array}{c}9777624 \\
, 97\end{array}$ & $\begin{array}{c}1159374 \\
7,87\end{array}$ & $\begin{array}{c}8740767 \\
, 60\end{array}$ & 33,85 & 67,50 & 60,16 & 17,66 & 3,73 & 11,00 & 6,91 & 16,90 \\
\hline Tôytil & 0,57 & 0,00 & 0,00 & 0,00 & 5 & 2 & 0,00 & 0,00 & 0,05 & 0,00 & 0,00 & $\begin{array}{c}0,00 \\
8368,0\end{array}$ & 0,00 & 0,05 & 11,39 & 33,64 & 7,70 & 2,57 \\
\hline $\begin{array}{l}\text { Têxtil } \\
\text { Min. N.-me }\end{array}$ & $\begin{array}{r}212,07 \\
277845\end{array}$ & $\begin{array}{l}31970,33 \\
104026,8\end{array}$ & 0,00 & 0,00 & 5136,89 & $\begin{array}{l}6174,53 \\
129431\end{array}$ & $\begin{array}{l}3072,53 \\
122396\end{array}$ & $\begin{array}{l}7008,92 \\
460610\end{array}$ & $\begin{array}{c}5651,82 \\
436878,2\end{array}$ & 360,85 & 0,07 & 6 & 0,25 & 0,77 & 8,13 & 0,16 & 0,01 & 206,45 \\
\hline Preciosos & 05 & 1 & 94748,03 & 2,97 & 8568,09 & $\begin{array}{c}77 \\
91208,7\end{array}$ & 52 & 09 & 9 & 0,65 & 7,77 & 0,69 & 0,04 & 0,79 & 0,23 & 0,14 & 6,93 & 0,44 \\
\hline $\begin{array}{l}\text { Metais comuns } \\
\text { Máquinas/ }\end{array}$ & 0,57 & 0,00 & 0,00 & 0,01 & 184,60 & $\begin{array}{c}91 \angle 08,1 \\
9\end{array}$ & 1,71 & 0,53 & 0,29 & 0,06 & 1,18 & 0,07 & 0,18 & 2,43 & 1,51 & 7,46 & 2,94 & 5,96 \\
\hline $\begin{array}{l}\text { equipamentos } \\
\text { Material }\end{array}$ & 0,00 & 0,01 & 0,00 & 0,02 & 0,00 & $\begin{array}{c}0,03 \\
18618,7\end{array}$ & 0,01 & $\begin{array}{c}0,02 \\
64772,5\end{array}$ & 0,01 & 0,00 & 0,03 & 0,01 & 0,01 & 0,01 & 0,08 & 0,09 & $\begin{array}{c}0,01 \\
1218404\end{array}$ & $\begin{array}{c}0,26 \\
131472,\end{array}$ \\
\hline $\begin{array}{l}\text { transporte } \\
\text { Ótica/ } \\
\text { instrumentos }\end{array}$ & 0,00 & 0,00 & 0,00 & 0,00 & 0,00 & 2 & 0,00 & 2 & 45814,49 & 0,00 & 0,00 & 0,00 & 0,00 & 0,00 & 0,00 & 0,21 & ,46 & 13 \\
\hline Outros & 0,57 & $\begin{array}{c}3362421 \\
22\end{array}$ & $\begin{array}{c}800004,6 \\
0\end{array}$ & $\begin{array}{c}239485,9 \\
9\end{array}$ & $\begin{array}{c}240451 \\
23\end{array}$ & $\begin{array}{c}20733,7 \\
7\end{array}$ & $\begin{array}{c}11117,6 \\
9\end{array}$ & $\begin{array}{c}21666,3 \\
9\end{array}$ & 30555,01 & 3558,68 & $\begin{array}{c}28593 \\
60\end{array}$ & $\begin{array}{c}99338 \\
40\end{array}$ & 0,18 & 0,00 & 0,26 & 0,43 & 0,04 & 0,58 \\
\hline
\end{tabular}

Fonte: Elaboração própria a partir dos dados MDIC (2017b). 
Em relação à taxa de cobertura do setor de madeira, pode-se destacar a importância desse setor para o estado, conforme destacado por Osorio (2016), ou seja, a madeira tem um significativo peso para as empresas industriais. Por exemplo, de acordo com o autor, só em 2013, do total exportado pelas empresas industriais no estado, 62,40\% corresponderam às exportações da indústria da madeira. Ainda segundo o autor, no estado, existe uma Zona de Processamento de Exportação (ZPE). Tal ZPE, que goza de benefícios e facilitações para exportações, no Acre, possui um perfil tipicamente agroindustrial, e a madeira é um dos destaques de produtos processados.

Em relação à taxa de cobertura do setor de calçados e couro, de acordo com López et al. (2008), existe um destaque para a exportação de couro vegetal no estado. Ainda nesta perspectiva, no estado do Acre, embora o mercado de couro vegetal ainda tenha que ser consolidado, o produto já é muito bem recebido e tem conseguido atrair a atenção e o apoio dos consumidores. Assim, em relação às exportações, novas possibilidades têm sido exploradas, especialmente no "mundo" da moda. Ainda nesta perspectiva, no estado, também está sendo produzido outro produto similar ao couro vegetal, conhecido como "couro ecológico", que, por meio de utilização de produtos químicos, não necessita do corte de árvores para a obtenção de lenha para a defumação do couro, o que é necessário no caso do couro vegetal.

Por último e não menos importante, o setor de alimentos, fumo e bebidas mereceu destaque em relação à taxa de cobertura $(T C>1)$, pois, desde 2006, vem se destacando, devido às exportações de castanhas. Para Bayma et al. (2014), a cadeia produtiva de castanha do Brasil, no estado do Acre, passou por um amplo e longo processo de estruturação, especialmente a partir do início da década de 2000. Diversas ações estruturantes foram feitas e, principalmente, viabilizadas pelo poder público - além da criação da central de cooperativas em 2001 - e pelo aumento da demanda do produto, tanto no mercado internacional como no nacional. Entretanto os autores ressaltam que, apesar de todas as mudanças, especialmente no aumento da capacidade industrial para processamento da castanha do Brasil, o estado ainda necessita melhorar sua capacidade de beneficiamento da castanha, visando a uma política de maior agregação de valor, que contribua para o fortalecimento e sustentabilidade dessa cadeia produtiva 


\section{Considerações finais}

Este estudo permitiu aprofundar as observações em relação ao padrão do comércio exterior dos diversos setores do estado do Acre. A visão integral dos resultados apresentados neste trabalho permitiu destacar as peculiaridades competitivas do Acre no comércio exterior, mostrando que apenas o setor de madeira é competitivo no comércio internacional. Os resultados do

IVCRS corroboram a competitividade do setor acreano de madeira, consequência de uma exploração consciente, com um manejo sustentável da madeira, e da instalação recente de uma Zona de Processamento de Exportação (ZPE) no estado. Quanto ao índice de Comércio Intraindústria (CII), os resultados alcançados apontaram que o comércio ainda não está sendo plenamente utilizado por nenhum setor acreano.

Com base nos resultados e levando em consideração que o índice de Comércio Intraindústria (CII) não apresentou resultados e que o Índice de Vantagens Comparativas Reveladas Simétricas (IVCRS) apresentou resultados satisfatórios apenas para o setor de madeira, chega-se à conclusão de que o estado do Acre demonstra um padrão de exportação baseado prioritariamente em produtos intensivos em recursos naturais, que são pouco capazes de gerar vantagens comparativas dinâmicas, ou seja, baseados em inovações tecnológicas, como as encontradas nos padrões internacionais de comércio dos países desenvolvidos.

Quanto ao Índice de Concentração Setorial (ICS), o estado do Acre apresenta uma pauta de exportações concentrada em poucos setores, com média do indicador de 0,69 , ao longo do período analisado, refletindo o IVCRS, visto que apenas um dos quatorze setores da pauta exportadora, o setor de madeira, apresentou vantagens comparativas, e, além disto, o Cll também indica que $100 \%$ dos setores apresentam comércio predominantemente baseado em vantagens comparativas, ou seja, interindustrial. Ainda, em relação à Taxa de Cobertura (TC) das importações, esta revela que, ao longo de todo o período, os setores com maiores taxas de cobertura foram os de madeira, calçados e couro, e alimentos, fumo e bebidas.

Em relação aos parceiros comerciais, a Bolívia se apresenta como o principal país importador, cenário diferente do observado em 1999, quando os Estados Unidos eram o 
maior comprador de produtos do Acre. Em relação ao padrão setorial das exportações, observa-se que houve mudanças na inserção setorial externa, na qual os produtos básicos vêm ultrapassando as exportações de semimanufaturados (que sofreram uma forte redução), ficando evidente tal configuração principalmente nos últimos anos da pesquisa.

Entre as limitações do trabalho, está o fato de os índices utilizados serem estáticos, ou seja, não permitirem análises intertemporais, fundamentais para a compreensão das diversas alterações econômicas. Neste sentido, fazem-se pertinentes análises mais robustas, utilizando modelos econométricos, bem como modelos que não sejam de equilíbrio parcial.

\section{Referências}

ALICEWEB. Análise das Informações de Comércio Exterior. Consultas. Disponível em: <http://aliceweb.mdic.gov.br/>. Acesso em: 15 jan. 2017.

APPLEYARD, D.; FIELD JR., A, J.; COBB, S. L. Economia Internacional. 6. ed. Porto Alegre: McGraw Hill, 2010.

AZEVEDO, G. G. de; ASSREUY, V. B. Manejo sustentável da madeira no Município de Xapuri-Ac. FGV-EAESP e EG-FJP, São Paulo, 2012.

BAYMA, M. M. A. et al. Aspectos da cadeia produtiva da castanha-do-brasil no estado do Acre, Brasil. Boletim do Museu Paraense Emílio Goeldi, v. 9, n. 2, 2014.

CASTRO, M. J.; FERNANDES, C. S.; CARVALHO, H. S. Estudo da cadeia de suprimento do setor madeireiro no estado do acre. O caso da empresa laminados triunfo. In: Anais Eletrônicos. IX SEGeT, Simpósio em Excelência em Gestão e Tecnologia, Rezende, 2012.

FARIAS, M. S. Percepção dos atores envolvidos no monitoramento do plano de manejo da reserva extrativista Chico Mendes, Acre, Brasil. 2013. 83 f. Monografia (Especialização em Gestão Florestal) - Secretaria de Desenvolvimento Florestal, da Indústria, do Comércio e dos Serviços Sustentáveis, Universidade Federal do Acre, Rio Branco, 2013.

FEISTEL, P. R. Modelo Gravitacional: um teste para economia do Rio Grande do Sul. Revista de Economia e Administração, v. 1, p. 94-107, 2008.

FRANCK, A. G. S. et al. Padrão de especialização do comércio internacional de Alagoas (1999-2016). Observatorio Economía Latinoamericana, Brasil, p. 1-23, maio 2017. 
GRUBEL, H.; LLOYD, P. Intra-Industry Trade: the theory and the measurement of international trade in differentiated products. London: Macmillan, 1975.

HIDALGO, A. B. Especialização e competitividade do Nordeste brasileiro no mercado internacional. Revista Econômica do Nordeste, Fortaleza: BNE, v. 29, p. 491-414, jul./set. 1998.

HIDALGO, A. B.; DA MATA, D. F. P. G. Exportações do Estado de Pernambuco: concentração, mudança na estrutura e perspectivas. Revista Econômica do Nordeste, Fortaleza, v. 35, n. 2, p. 264-283, abr./jun. 2004.

HIDALGO, A. B.; FEISTEL, P. R. Mudanças na estrutura do comércio exterior brasileiro: uma análise sob a ótica da teoria de Heckscher-Ohlin. Estudos Econômicos, v. 43, n. 1, p. 79-108, jan./mar. 2013.

ILHA, A. S.; DORNELLES, J. P.; WEGNER, R. C. Padrão de Comércio Internacional e Competitividade: Análise do Intercâmbio Comercial Industrial do Rio Grande do Sul (1996-2006). Revista Economia e Desenvolvimento, n. 21, p. 45-61, 2009.

IBGE. Instituto Brasileiro de Geografia e Estatísticas. Perfil dos Estados. Disponível em: <http://www.ibge.gov.br/estadosat/perfil.php?sigla=ac>. Acesso em: 9 fev. 2017.

LÓPEZ, C. et al. Riquezas da floresta: frutas, plantas medicinais e artesanato na América Latina. Bogor: CIFOR, 2008.

MAIA, S. F. Transformações na estrutura produtiva do estado do Paraná na década de 90: análise por vantagem comparativa. In: MAIA, S. F.; MEDEIROS, N. H. (Orgs.). Transformações Recentes da Economia Paranaense, Recife, Universitária, v. 1, p. 65-88, 2005.

MARCONI, N. ROCHA, M. Taxa de câmbio, comércio exterior e desindustrialização precoce o caso brasileiro. Economia e Sociedade, Campinas, v. 21, n. Especial, p. 853-888, dez. 2012.

MINISTÉRIO DO DESENVOLVIMENTO, INDÚSTRIA E COMÉRCIO EXTERIOR (MIDIC). Balança Comercial. 2017a. Disponível em: <http://www.mdic.gov.br/comercio-exterior/estatisticasde-comercio-exterior/balanca-comercial-brasileira-unidades-da-federacao>. Acesso em: 8 fev. 2017.

MINISTÉRIO DO DESENVOLVIMENTO, INDÚSTRIA E COMÉRCIO EXTERIOR (MIDIC). Séries Históricas. 2017b. Disponível em: <http://www.mdic.gov.br/comercio-exterior/estatisticasde-comercio-exterior/series-historicas>. Acesso em: 8 fev. 2017.

MUNDURUCA, D. F. V.; SANTANA, J. R. de. Comércio exterior como estratégia de crescimento econômico: uma proposta de priorização de produtos exportáveis para a economia sergipana. Documentos Técnico-Científicos, v. 43, n. 3, 2012. 
OSORIO, F. C. A questão fitossanitária em zonas de processamento de exportação: o caso do ZPE Acre. 2016. 58 f. Dissertação (Mestrado profissional em Defesa Sanitária Vegetal) Universidade Federal de Viçosa, Viçosa. 2016.

PAGANINI, C. C.; FRAGA, G. J. Padrão de especialização do comércio internacional do Paraná no período 2001-2011. Revista Paranaense de Desenvolvimento, Curitiba, v. 35, n. 127, p. 135-154, jul./dez. 2014.

SILVA, R. A. da et al. Padrão de especialização do comércio internacional do Rio Grande do Sul (1999-2016). Revista eletrônica científica do CRA-PR, v. 4, n. 1, p. 1-19, 2017.

SILVA, R. G. Avaliação da Política de Subvenção Econômica à Borracha Natural no Estado do Acre. Espacios, v. 36, n. 20, 2015.

XAVIER, C. L.; SILVA. K. A. O. da. Padrão de especialização e competitividade das exportações de Minas Gerais no período 1995-2004. Revista Econômica do Nordeste, Fortaleza, v. 38, n. 4, p. 563-582, out./dez. 2007. 